\title{
ELECTRON MICROSCOPIC OBSERVATION ON THE POLYMERIZED MATERIALS FROM $\beta$-ALANINE SINGLE CRYSTAL IN THE SOLID STATE
}

\author{
Hirokazu Kimura, Hiroshi Sakabe, Takashi Itoh, and Takashi Konishi \\ Department of Polymer Science, Kyoto Institute of Technology \\ Matsugasaki, Sakyo-ku, Kyoto, 606 Japan
}

\begin{abstract}
Morphology of poly $(\beta$-alanine $)$ crystal, which was formed through the thermal solid state polycondensation procedure from $\beta$-alanine monomer single crystal, was observed mainly by means of scanning and transmission electron microscopy. In the early stage of the polymerization reaction at $150^{\circ} \mathrm{C}$, the surface of the specimen was found to be covered by the aggregation of the rod-like materials (ca. $1 \mu \mathrm{m}$ thick and $10 \mu \mathrm{m}$ long). The fibrillar structure was observed on the surface in the final stage of the reaction. Each fibril is about $100 \mathrm{~nm}$ in diameter. Decreasing the reaction temperature to $130^{\circ} \mathrm{C}$, it was found on the basis of the X-ray diffraction results that the direction of the polymer chains corresponds to the long axis of the monomer molecules in the original monomer single crystal. There were two principle directions for the morphological fiber axis and the fibrils overlapped each other crosswise.
\end{abstract}

\section{INTRODUCTION}

It is well-known that several $\omega$-amino acids are polymerized by heat treatment in the solid state. For example, the single crystal of $\varepsilon$-aminocaproic acid has been reported to be converted into the biaxially oriented nylon 6 crystal by the thermal solid polymerization [1-3].

Macchi [4] found that the biaxially oriented nylon 11 was also produced from 11-aminoundecanoic acid single crystal by long-time annealing below its melting point. Ikawa et al. [5] recently found that nearly perfect nylon 12 single crystal could be obtained by the solid state polycondensation of 12-aminododecanoic acid under high pressure. Some of us $[6,7]$ have reported that single crystals of glycine and $\beta$-alanine were transformed into the polyamide crystals by the thermal solid state polymerization; the former becomes the type-I crystal of poly(glycine) and the latter changes to the type-I modification of nylon 3 crystal.

In this study, morphological change in the crystal of poly $(\beta$-alanine $)$ produced by such polymerization reaction in the solid state is examined by scanning (SEM) and transimission (TEM) electron microscopy as well as the changes in the crystal structure and its orientation during the reaction process, which are analyzed by $\mathrm{X}$-ray diffraction technique.

\section{EXPERIMENTAL}

Commercial $\beta$-alanine(Nakarai Tesque, Inc.) was recrystallized from the distilled water solution by the procedure shown in Fig. 1.

The perfect single crystals finally obtained were about $10 \mathrm{~mm}$ in size and used as the original speci. mens. Such specimens were polymerized in the evacuated glass tube immersed in a silicon oil bath, the temperature of which was maintained at $105^{\circ} \mathrm{C}$ for 2 days and increased up to $130^{\circ} \mathrm{C}$ or $150^{\circ} \mathrm{C}$. The specimens were kept at the constant temperature $\left(130^{\circ} \mathrm{C}\right.$ or $\left.150^{\circ} \mathrm{C}\right)$ for several days.

The surface morphology of the specimen was observed on a Hitachi 410 SEM with an accelerating voltage of $5 \mathrm{kV}$ after being coated with gold. Ionic etching was performed for some specimens using an Eiko IB-3 apparatus with DC current of $3 \mathrm{~mA}$ for 15 min. Thin films about $100 \mathrm{~nm}$ thich were prepared for TEM observation by casting the dilute dichlor. oacetic acid solution of the polymerized $\beta$-alanine $(0.5 \mathrm{mg} / \mathrm{mL})$ onto the carbon-coated fresh mica plate 


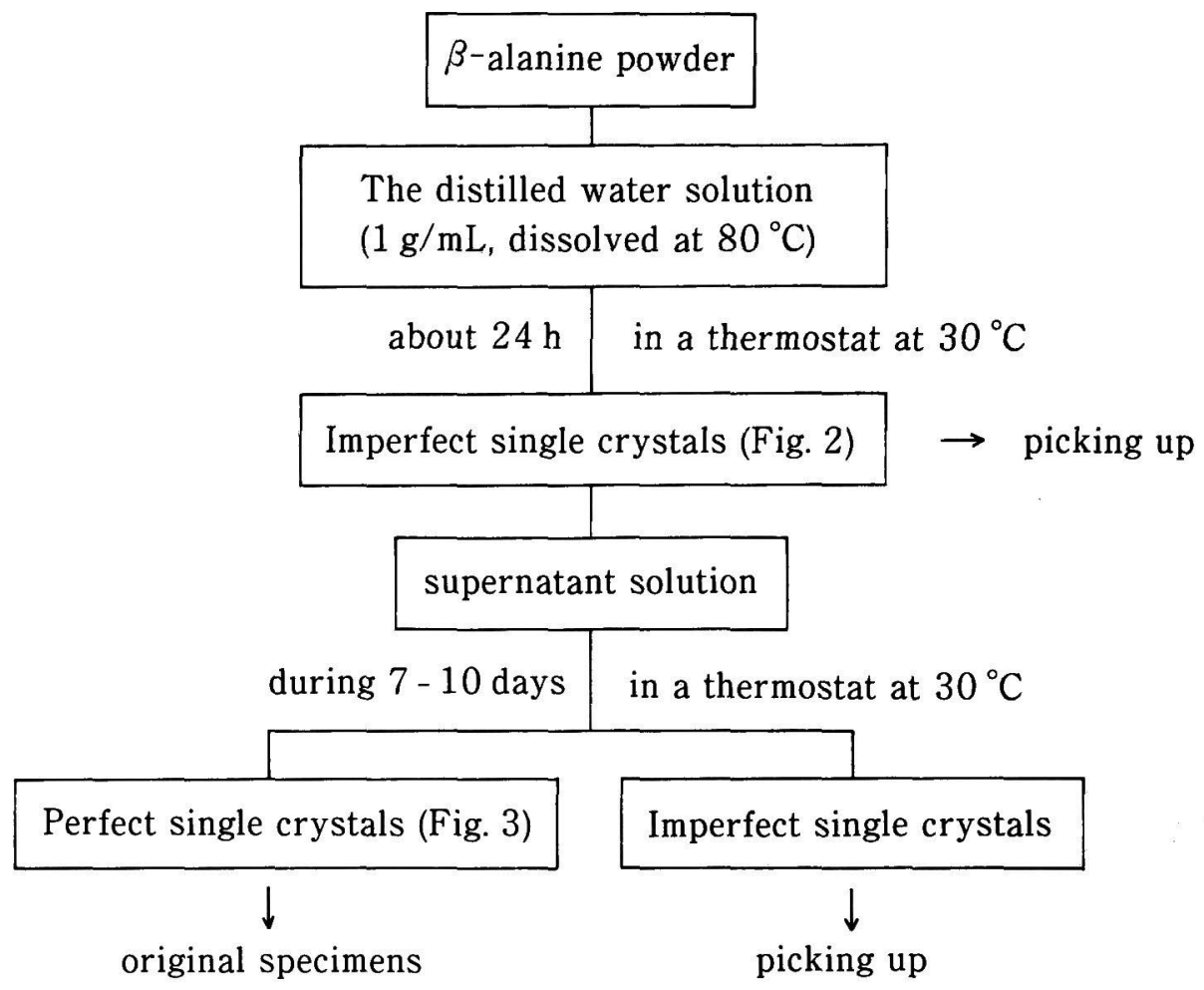

Fig. 1. Procedure to prepare the $\beta$-alanine single crystals.

at $30^{\circ} \mathrm{C}$. The thin films were floated on the distilled water and picked up onto 150 mesh TEM grids, which were observed in a JOEL JEM 100-C TEM with an accelerating voltage of $100 \mathrm{kV}$. The X-ray diffraction photographs were taken with a flat-plate camera mounted on an X-ray generator (Rigaku, Cat. No. $4001 \mathrm{~A}$ ) with $\mathrm{Ni}$-filtered $\mathrm{CuK} \alpha$ radiation.

\section{RESULTS AND DISCUSSION}

It was observed that the single crystals of $\beta$ alanine precipitated from the distilled water solution and continued to grow gradually during about 1 day in the solution kept at $30^{\circ} \mathrm{C}$ in a thermostat. Few single crystals, however, were found to be perfect at this stage. The imperfect crystals were turbid and some of them looked like twin as shown in Fig. 2. The turbidity of imperfect crystals seems to be attributed dislocations and / or defects in the crystalline lattice. After such imperfect crystals in visible size were picked up to be discarded, the solution was filtrated

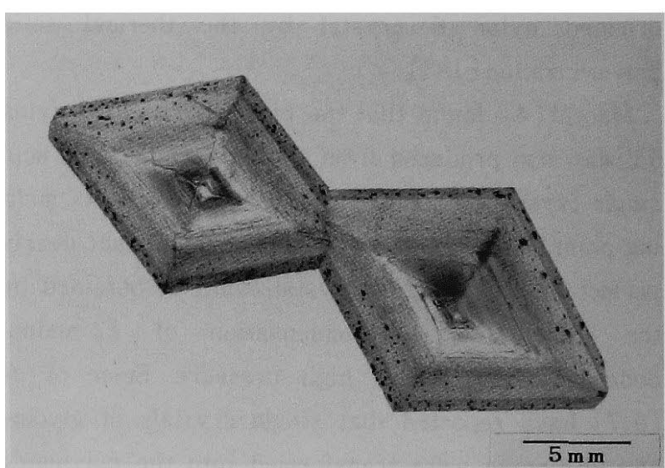

Fig. 2. A photograpl of the twin-type imperfect crystal of $\beta$-alanine.

to remove some invisible impurities. The filtrate was kept in a thermostat at $30^{\circ} \mathrm{C}$. After 7 to 10 days, single crystals with rhombic habit and clear planes of cleavage grew in the solution. These crystals were colorless and transparent, a picture of which is shown in Fig. 3. We regard such crystals as perfect 


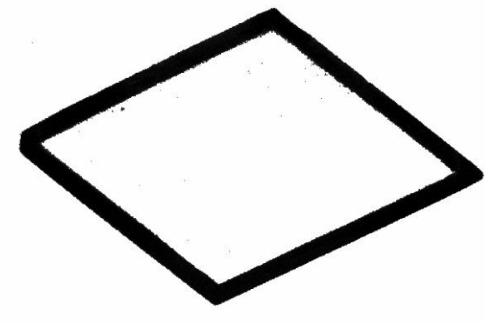

$5 \mathrm{~m} \mathrm{~m}$

Fig. 3. A photograph of a perfect single crystal of $\beta$ alanine.

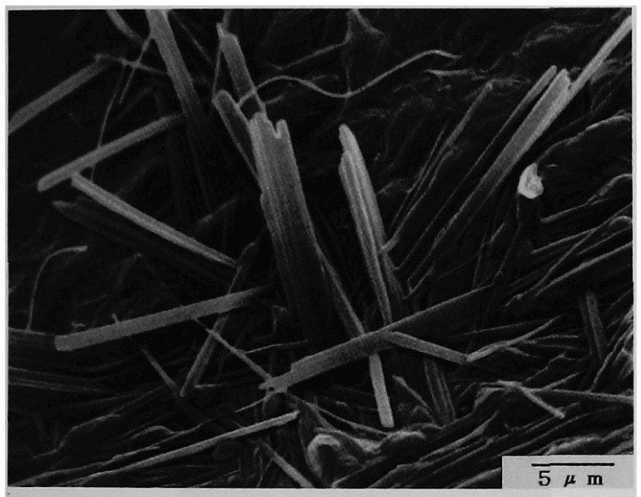

Fig. 4. A SEM photograph of the surface of the crystal polymerized at $150{ }^{\circ} \mathrm{C}$ for $70 \mathrm{~h}$.

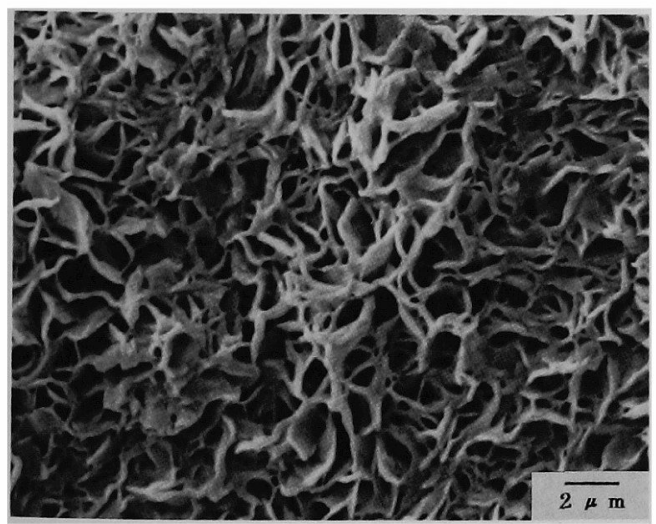

Fig. 5. A SEM photograph of the surtace of the crystal polymerized at $150^{\circ} \mathrm{C}$ for $70 \mathrm{~h}$ and immersing in hot wa. ter $\left(80^{\circ} \mathrm{C}\right)$ subsequently. The same specimen as that of Fig. 4 was used in this case.

single crystals of $\beta$-alanine.

The solid-state polymerization procedure was per

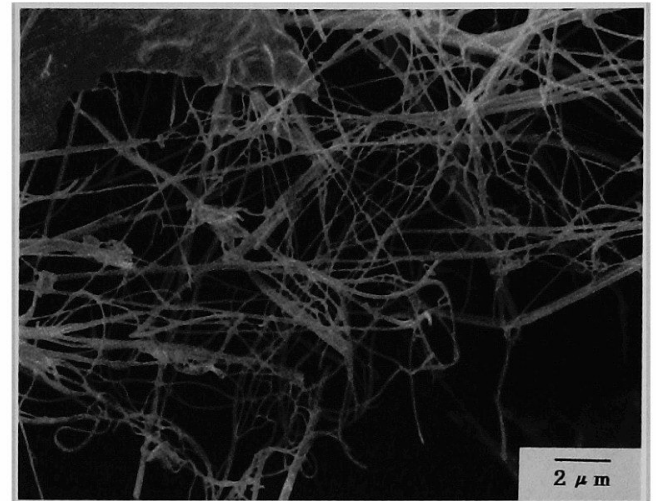

Fig. 6. A SEM photograph of the surface of the crystal polymerized at $150{ }^{\circ} \mathrm{C}$ for $120 \mathrm{~h}$.

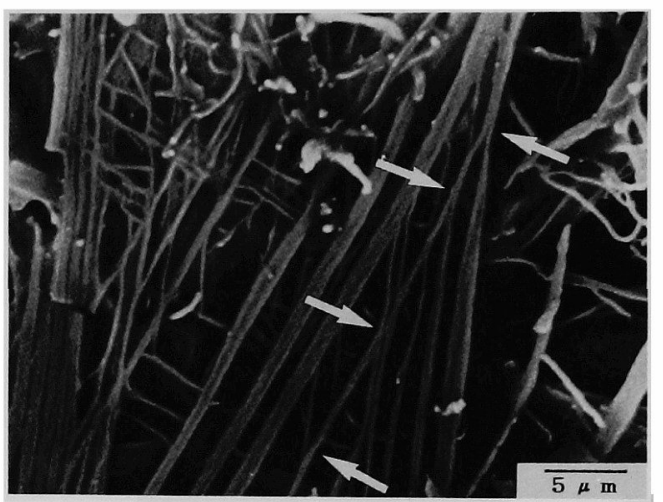

Fig. 7. A SEM photograph of the surface of the crystal polymerized at $150^{\circ} \mathrm{C}$ for $100 \mathrm{~h}$. The arrows show the branch points where the fibrils separate from the rods.

formed by using the perfect single crystals of the monomer. In the early stage of the polymerization process (several tens of hours) at $150{ }^{\circ} \mathrm{C}$, many rectangular rods were observed over the surface of specimen as shown in Fig. 4. The rods are considered to be mainly composed of oligomer or monomer of $\beta$ alanine since such morphology disappeared after the specimen was immersed in hot water $\left(80^{\circ} \mathrm{C}\right)$ as shown in Fig. 5 . When the specimen was polymerized at 150 ${ }^{\circ} \mathrm{C}$ for $120 \mathrm{~h}$, fibrillar materials were found to be produced on the surface of the crystal as shown in Fig. 6. Such fibrils seem to be generated from the rod shaped materials. Fig. 7 shows separation of the fibrils from the rods (the arrows indicate the branch points) on the surface of the crystal polymerized at $150{ }^{\circ} \mathrm{C}$ for $100 \mathrm{~h}$.

In the case of the lower temperature polymerization 
$\left(130^{\circ} \mathrm{C}\right)$, laminating structure of thin rhombic plates appeared on the surface of the specimen as shown in Fig. 8.

Two types of X-ray diffraction patterns are shown

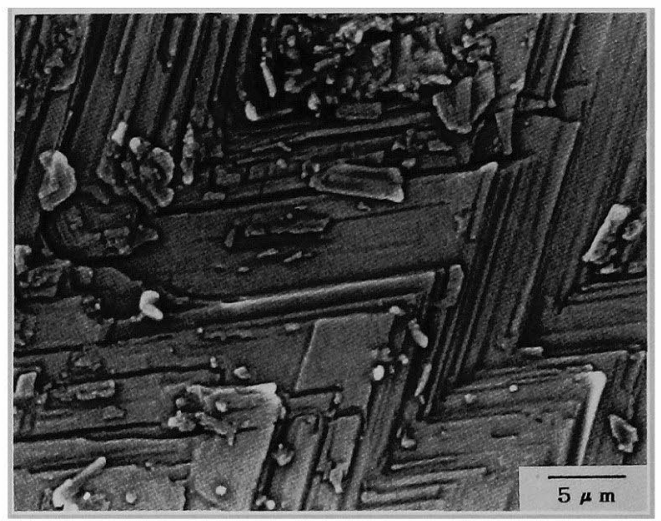

Fig. 8. A SEM photograph of the surface of the crystal polymerized at $130^{\circ} \mathrm{C}$ for $120 \mathrm{~h}$. in Fig. 9, where (a) was obtained from the specimen fully polymerized at $150^{\circ} \mathrm{C}$ for $120 \mathrm{~h}$ and (b) was from that insufficiently polymerized at $130^{\circ} \mathrm{C}$ for $480 \mathrm{~h}$. The diffraction pattern of Fig. 9(a) shows two Debye-Scherrer rings, which can be indexed as 200 (inner ring) and 002 (outer one) of type-I modification of nylon 3 as described by Masamoto et al. [8]. Such a pattern indicates that the degree of crystalline orientation in this specimen is very low. Any $0 \mathrm{k} 0$ reflection relating with the fiber axis was not observed. In the case of Fig. 9(b), three intense reflections were observed. The most inner arc is considered to be 010 reflection, d-spacing of which corresponds to the fiber axis period $(0.48 \mathrm{~nm})$ of type-I modification of nylon 3 . Such a diffraction pattern suggests the high degree of orientation for the fiber axis in this crystal. The SEM picture of this specimen with higher magnification is shown in Fig. 10, where the fibrils overlap

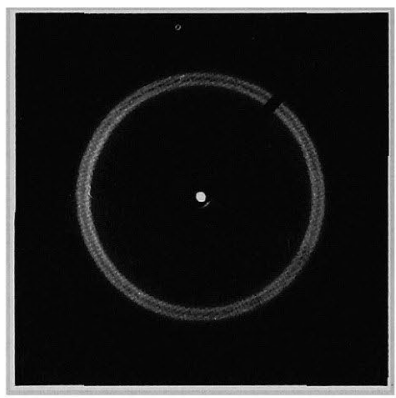

( a )

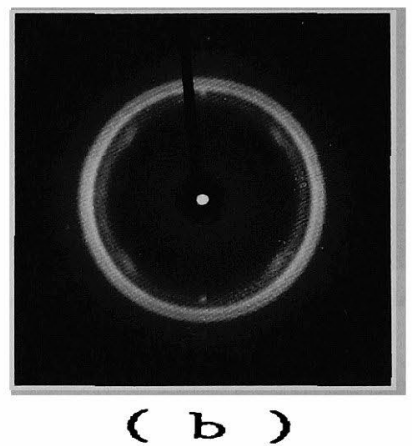

Fig. 9. X-ray diffraction patterns taken from the crystals polymerized (a) at $150{ }^{\circ} \mathrm{C}$ for $120 \mathrm{~h}$ and (b) at $130{ }^{\circ} \mathrm{C}$ for $480 \mathrm{~h}$.

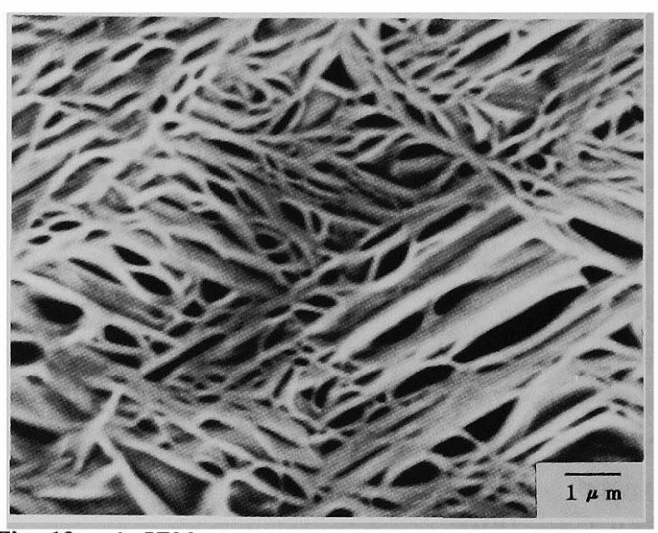

Fig. 10. A SEM photograph of the surface of the crystal polymerized at $130{ }^{\circ} \mathrm{C}$ for $120 \mathrm{~h}$.

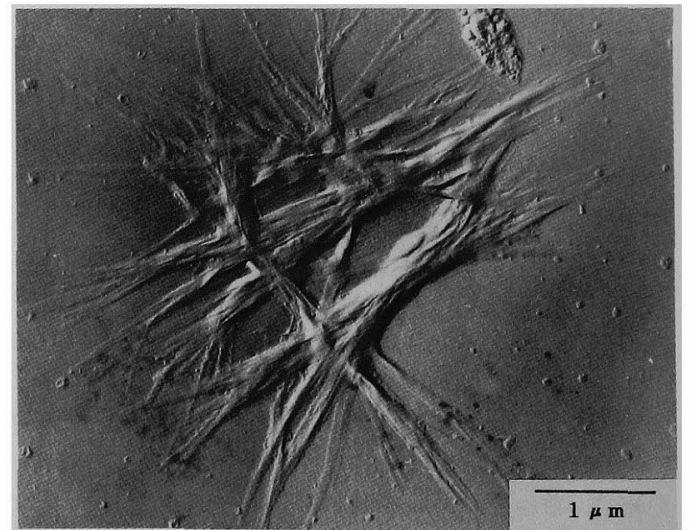

Fig. 11. A TEM photograph of the thin film cast from the dilute solution of poly( $\beta$-alanine). 
each other crosswise. There are two principle directions to which the morphological long axis of the fibrils align parallel. On the basis of the X-ray diffraction patterns from the same specimen, it was found that the direction of the polymer chains corresponds to the long axis of the monomer molecules in the original $\beta$-alanine single crystal.

Fig. 11 shows a TEM picture of thin film cast from the $0.05 \%$ dichloroacetic acid solution at $30^{\circ} \mathrm{C}$. The sheaf-like aggregation of the lamella crystals was observed as shown in the picture. Such type of morphological structure is generally observed in other synthetic polymer spherulites.

\section{REFERENCES}

1. E. M. Masshi, N. Morosoff, and H. Morawetz, $J$.
Polym. Sci., A--1, 6, $2033-2049$ (1963)

2. T. Yamazaki, Doctral Thesis, Kyoto Unv. (1985)

3. S. Ohya, M. Tomioka, and T. Araki, Kobunshi Kagaku, 23, 415 (1966)

4. E. M. Masshi, Macromol. Chem., 180, 1603 (1979)

5. T. Ikawa, K. Shimamura, F. Yokoyama, K. Monobe, Y. Mori, and Y. Tanaka, Sen'i Gakkaishi., 42, T403 (1986)

6. T. Konishi, T. Haneda, and H. Kimura, Kobunshi Ronbunshu, 41, 51 (1984)

7. H. Sakabe, H. Nakamura, H. Kimura, and T. Konishi, Sen ¿ Gakkaishi, 45, 493 (1989)

8. J. Masamoto, H. Kobayashi, Kobunshi Kagaku, 27, $220(1970)$ 